\title{
Heavy oil viscosity and density prediction at normal and elevated temperatures
}

\author{
Osamah Alomair $^{1} \cdot$ Mohammad Jumaa $^{2}$ Abullhaq Alkoriem ${ }^{1} \cdot$ Mohamed Hamed $^{1}$
}

Received: 28 December 2014/ Accepted: 17 May 2015/Published online: 2 June 2015

(C) The Author(s) 2015. This article is published with open access at Springerlink.com

\begin{abstract}
Viscosity and density are important physical properties of crude oil. However, no practical theory exists for the calculation of these properties for heavy oil at elevated temperatures. The principal objective of this paper is to obtain exact models that can successfully predict these two important fluid properties covering a wide range of temperatures. In this study, heavy oil density was predicted from API and temperature, and then the predicted values of the densities were used in the second step to develop the viscosity correlation. A total of 30 heavy oil samples of different API gravities ranging from 11.7 to 18.8 were tested. Viscosity and density were measured in the temperature range from 20 to $160{ }^{\circ} \mathrm{C}$. The accuracy of the experimental density data was determined using Standing and Katz method. Published correlations were also used to evaluate the experimental viscosity data. The comparison between the experimental data and the predicted values indicated that the proposed model successfully predicted the experimental data with an average absolute relative error of less than $8 \%$ and correlation coefficients $\left(R^{2}\right)$ of 0.97 and 0.92 at normal and high temperatures, respectively. The proposed model and the literature models were tested on heavy oil samples. It was found that it is not possible to generalize a correlation for the heavy oil viscosity using only API and temperature. However, the proposed model significantly minimizes the relative error
\end{abstract}

Osamah Alomair

dr-alomair@hotmail.com

1 Kuwait University, Safat, P.O.Box 5969, 13060 Kuwait, Kuwait

2 Kuwait Institute for Scientific Research, Kuwait, Kuwait and increases the correlation between the predicted and experimental data compared with other published methods.

Keywords Heavy oil · Viscosity · Density $\cdot$ Elevated temperature

\section{Introduction}

Recent developments in improved oil technologies have increased the demand for heavy oil in the international market. Crude oil is classified as light or heavy oil based on different physical properties, such as molecular weight, viscosity, density, and API gravity. The most common definition of heavy crude oil is crude oil with API gravity less than 20, according to the International Energy Agency (IEA) and US geological survey (USGS). Viscosity and density play very important roles in oil production, transportation through pipelines, and oil recovery processes. Obtaining reliable viscosity and density measurements can be difficult, especially for live oil. These properties are very important and should be evaluated precisely for reservoir simulation. Measuring the viscosity and the density of dead oil is easier using empirical correlations at temperatures other than the reservoir temperatures (Ahrabi et al. 1987). These dead oil measurements can be used as the starting point for live oil viscosity and density predictions. The difficulty and high costs of viscosity and density measurements at reservoir conditions are the main reasons for the lack of such data at other temperatures. Additionally, viscosity and density are important guidelines for numerical simulations to determine the economics of the Enchanted oil recovery (EOR) project and the success or failure of a given EOR scheme. Consequently, a correlation must estimate these values under different temperatures 
(Miller 1995). The viscosity of crude oil depends on many factors, such as the source chemical composition (Sattarin et al. 2007). Therefore, developing a comprehensive model of viscosity to include different regions of the world seems to be a very challenging task. Several correlations for predicting dead oil viscosity are available in the literature. Some of these models are discussed in this paper, such as the Beggs and Robinson (1975) model for temperatures ranging from 21 to $146{ }^{\circ} \mathrm{C}$ and the Elsharkawy and Alikhan (1999) model based on crude oil samples from the Middle East for temperatures ranging from 38 to $150{ }^{\circ} \mathrm{C}$. Naseri et al. (2005) presented a model for temperatures ranging from 40 to $146{ }^{\circ} \mathrm{C}$. Other authors suggest that the variation in compositions is why correlating the viscosity of heavy crude with high accuracy is improbable (Beal 1946). Beal created a chart that described the viscosities of 655 dead oil samples at $38{ }^{\circ} \mathrm{C}$, representing 492 oil fields around the world and covering viscosities ranging from 0.8 to $155 \mathrm{cP}$, gravities ranging from $10.1^{\circ}$ to $52.5^{\circ} \mathrm{API}$ and temperatures from 38 to $105{ }^{\circ} \mathrm{C}$. In addition, Kartoatmodjo and Schmidt (1994) developed an empirical correlation to predict the viscosity of dead oil with 3588 data points from 661 dead oil samples that covered gravities ranging from $14.4^{\circ}$ to $58.9^{\circ} \mathrm{API}$, viscosities ranging from 0.5 to $682 \mathrm{cP}$, and temperatures ranging from 75 to $320^{\circ} \mathrm{F}$. Labedi (1992) also correlated the dead oil viscosity in the range of 0.66 to $4.79 \mathrm{cP}$ and gravity in the range from $32.2^{\circ}$ to $48.0^{\circ} \mathrm{API}$ as a function of API gravity and temperature covering the range from 38 to $152^{\circ} \mathrm{C}$. Using 91 data points, Labedi (1992) claimed that his equation was more accurate than previous efforts (Beal 1946) and (Beggs and Robinson 1975), which might have been true for this tight viscosity range; however, large errors were observed when this model was applied outside of these temperature, viscosity, or API ranges. Hossain et al. (2005) statistically analyzed a data bank covering the dead oil viscosity range of $22-415 \mathrm{cP}$ and the temperature range of 51 to $93^{\circ} \mathrm{F}$ for oil samples with gravities in the range of $15.8^{\circ}$ to $22.3^{\circ} \mathrm{API}$. In this work, a temperature range between $20 \mathrm{C}$ and $160 \mathrm{C}$ was set to perform the experimental measurements of viscosity and density of the dead oil samples. This range was chosen because this is the most common range of operation in reservoirs and pre-refinery processes.

\section{Experimental details}

\section{Sample preparation}

Samples of dry heavy crude oil were collected in specially designed 2.5-L glass stoppered bottles and were stored at $20{ }^{\circ} \mathrm{C}$. The crude oil samples were mixed with an emulsion breaker (commercial-grade Nalco demulsifier), centrifuged to remove the traces of basic sediments and water $(\mathrm{BS} \& \mathrm{~W})$, and finally the samples were maintained in an oven at $40{ }^{\circ} \mathrm{C}$. Prior to the analysis, each sample was shaken vigorously using open-air platform shakers to achieve homogeneity. As soon as the bottles were opened, the water contents of the samples were measured with a Metrohm KF (model 832-Thermoprep), and the moisture range was measured to be between $10 \times 10^{-4}$ and $5 \times 10^{-3} \mathrm{~g} \mathrm{~g}^{-1}$. Before each test, all instruments were calibrated according to the manufacturer's specifications. As per the test procedures, triplicate measurements were performed, and the average was used. Descriptive statistics of the tested samples (API, temperature, viscosity, and density) are shown in Table 1.

\section{Density and viscosity measurements}

The dynamic viscosity, $\mu$, of 30 dead crude oil samples in the temperature range from 20 to $160{ }^{\circ} \mathrm{C}$ was determined using an electromagnetic viscometer. The viscometer consists of two coils that move the piston back and forth magnetically with a constant force. Proprietary circuitry analyzes the piston's two-way travel time to measure the absolute viscosity. The instrument was calibrated by measuring in triplicate the three reference samples, N600, N2000, and N4000, supplied by Canon Instruments. The calibration was done for the temperature range of interest with a reproducibility of $\pm 0.95 \%$. The estimated uncertainty of the dynamic viscosity for all the measured ranges was not more than $9 \times 10^{-3} \mathrm{mPa}$ s at $95 \%$ confidence interval. The densities were measured at temperature intervals between 20 and $160{ }^{\circ} \mathrm{C}$ using an oscillating U-tube densitometer; the oscillation period in the vibrating $U$ tube of the densitometer was converted to density using Eq. 1.

$\rho=A \tau^{2}-B$,

where $\rho$ is the density in $\mathrm{kg} \mathrm{m}^{-3}$ and $\tau$ is the tube oscillation period in seconds, the apparatus constants $(A$ and $B$ ) were determined by using the density of dry air and ultrapure water at the temperature of interest. The temperature of the measuring cell is controlled using two integrated measuring sensors (Pt100) with a temperature

Table 1 Descriptive statistics of the 376 experimental data points of the 30 samples

\begin{tabular}{lclll}
\hline & API $60\left({ }^{\circ} \mathrm{F}\right)$ & $T\left({ }^{\circ} \mathrm{C}\right)$ & $\mu(\mathrm{cP})$ & $\rho\left(\mathrm{g} / \mathrm{cm}^{3}\right)$ \\
\hline Mean & 16.1 & 81 & 281.2 & 0.9 \\
Standard Error & 0.1 & 4.1 & 52.9 & 0.0 \\
Standard Deviation & 1.8 & 79 & $1.0 \times 10^{3}$ & 0.03 \\
Sample Variance & 3.4 & 6366 & $1.0 \times 10^{6}$ & $1.0 \times 10^{-3}$ \\
Minimum & 11.7 & 20 & 1.7 & 0.8 \\
Maximum & 18.8 & 160 & $1.1 \times 10^{4}$ & 1.0 \\
\hline
\end{tabular}


Table 2 TBP distillation range of 10 crude oil samples according to ASTM D2892 and ASTM D5236

\begin{tabular}{|c|c|c|c|c|c|c|c|c|c|c|c|}
\hline Sample\# & $5(\%)$ & $12(\%)$ & $20(\%)$ & $32(\%)$ & $40(\%)$ & $50(\%)$ & $61(\%)$ & $69(\%)$ & $80(\%)$ & $90(\%)$ & Residue \\
\hline & \multicolumn{11}{|c|}{ Distillation Temperature $\left({ }^{\circ} \mathrm{C}\right)$} \\
\hline 1 & 94 & 116 & 164 & 225 & 260 & 320 & 390 & 435 & 506 & 585 & 616 \\
\hline 2 & 108 & 140 & 195 & 255 & 299 & 360 & 410 & 463 & 533 & 611 & 644 \\
\hline 3 & 115 & 158 & 210 & 266 & 315 & 372 & 437 & 503 & 554 & 657 & 690 \\
\hline 4 & 104 & 131 & 182 & 239 & 285 & 347 & 420 & 483 & 561 & 635 & 665 \\
\hline 5 & 115 & 180 & 230 & 288 & 322 & 373 & 427 & 480 & 555 & 627 & 666 \\
\hline 6 & 110 & 150 & 208 & 270 & 305 & 354 & 418 & 499 & 549 & 623 & 675 \\
\hline 7 & 135 & 170 & 215 & 285 & 315 & 355 & 415 & 519 & 580 & 681 & 705 \\
\hline 8 & 123 & 144 & 187 & 228 & 292 & 363 & 490 & 535 & 550 & 655 & 720 \\
\hline 9 & 129 & 174 & 220 & 247 & 283 & 343 & 495 & 523 & 553 & 665 & 733 \\
\hline 10 & 140 & 182 & 230 & 265 & 292 & 352 & 501 & 555 & 590 & 683 & 755 \\
\hline
\end{tabular}

Table 3 Critical properties and acentric factors of the different pseudo-components of the crude oil samples

\begin{tabular}{lllll}
\hline Sample & $\mathrm{T}_{\mathrm{c}}{ }^{\circ} \mathrm{C}$ & $\mathrm{P}_{\mathrm{c}}\left(\mathrm{Pa} \times 10^{-6}\right)$ & $\omega$ & $\mathrm{Mw}$ \\
\hline 1 & 536.42 & 1.92 & 0.71 & 248 \\
2 & 551.80 & 1.80 & 0.75 & 267 \\
3 & 567.64 & 1.57 & 0.84 & 299 \\
4 & 566.13 & 1.65 & 0.81 & 290 \\
5 & 586.06 & 1.61 & 0.84 & 307 \\
6 & 570.69 & 1.57 & 0.84 & 301 \\
7 & 587.95 & 1.58 & 0.85 & 312 \\
8 & 562.25 & 1.74 & 0.78 & 278 \\
9 & 585.17 & 1.67 & 0.82 & 299 \\
10 & 574.56 & 1.84 & 0.75 & 276 \\
\hline
\end{tabular}

reproducibility of $\pm 10^{-2}{ }^{\circ} \mathrm{C}$. The calibration was done at the temperatures of interest by using ultrapure water. Triplicate density measurements were performed for all the samples. The results were averaged, and the estimated uncertainty of the measurements was within $0.5 \mathrm{~kg} \mathrm{~m}^{-3}$.

\section{True boiling point (TBP) determination}

Ten dead oil samples out of the 30 samples were selected that covered the entire range of API values. The TBP distillation was carried out in the AUTODEST 800 Fisher $\mathrm{GmbH}$ backed column, equivalent to 15 -trayes according to ASTM D 2892 for the test exposed to the atmosphere and according to ASTM D 5236 for the test under vacuum. The TBP distillation was performed at a pressure drop ranging from 760 to $2 \mathrm{mmHg}$ with a reflux ratio of 1:5. The specific gravity at $60{ }^{\circ} \mathrm{F}$, API gravity, dynamic viscosity, and true boiling point for each fraction were measured as shown in Tables 2 and 3 . The critical properties of each sample are calculated in Table 4.

\section{Results and discussion}

\section{Proposed models}

The experimental data of the viscosity and the density of 30 dead heavy oil samples with different API values were measured in the temperature range of $20-160{ }^{\circ} \mathrm{C}$. These values were subjected to a simple statistical analysis to assess the distribution of the data points (Table 1). The correlation coefficients were estimated to determine and to evaluate the strength of the dependency between each of these two variables. The correlation coefficient for viscosity-density is positive, whereas the coefficient for viscosity-temperature is negative (Table 5). Thus, the viscosity is directly proportional to density and inversely proportional to temperature, with high correlation between the data. The ASTM indicates that dead oil viscosity is labeled according to its standard API at $15.5^{\circ} \mathrm{C}$. This value is the first parameter for any model, and the second parameter is the value of the measured temperature. According to literature reviews, most of the models are based on an intermediate parameter or sometimes two parameters, the API and temperature, to calculate the viscosity (Ahrabi et al. 1987; Little \& Kennedy 1968; Lohrenz et al. 1964). In most cases, this parameter has no physical meaning. Therefore, a real physical property was selected as the intermediate parameter, such as density, and the density was modeled using API and temperature. The goal was to create models in the following formats for the density and viscosity predictions

$\rho_{\text {od }}=f\left(T, A P I_{@ 60 o F}\right)$

$\mu_{\mathrm{od}}=f\left(T, \rho_{o d}\right)$,

where $\rho_{\text {od }}$ is the density of the dead oil in $\mathrm{kg} \mathrm{m}^{-3}, \mu_{\text {od }}$ is the viscosity of the dead oil in $\mathrm{cP}, T$ is the temperature in 
Table 4 Properties of the different pseudo-components of the crude oil samples

\begin{tabular}{llll}
\hline Sample\# & $\mathrm{API}_{60}\left({ }^{\circ} \mathrm{F}\right)$ & $T_{\mathrm{b}}\left({ }^{\circ} \mathrm{C}\right)$ & $\mathrm{SG}_{\mathrm{i}}$ \\
\hline 1 & 18.24 & 336.33 & 0.94 \\
2 & 17.60 & 355.00 & 0.95 \\
3 & 18.87 & 380.67 & 0.94 \\
4 & 17.76 & 375.00 & 0.95 \\
5 & 15.13 & 393.67 & 0.96 \\
6 & 18.39 & 383.33 & 0.94 \\
7 & 15.44 & 397.33 & 0.96 \\
8 & 16.82 & 366.67 & 0.95 \\
9 & 14.23 & 389.33 & 0.97 \\
10 & 13.18 & 371.33 & 0.978 \\
\hline
\end{tabular}

Table 5 Correlation factors between API, $T, \mu$ and $\rho$

\begin{tabular}{lllll}
\hline Designation & $\begin{array}{l}\text { API } \\
{ }_{60}\left({ }^{\circ} \mathrm{F}\right)\end{array}$ & $T$ & $\mu$ & $\rho$ \\
\hline API ${ }_{60}\left({ }^{\circ} \mathrm{F}\right)$ & 1 & & & \\
$T$ & 0.90472 & 1 & & \\
$\mu$ & -0.23785 & -0.90432 & 1 & \\
$\rho$ & -0.74778 & -0.92887 & 0.846399 & 1 \\
\hline
\end{tabular}

degree Celsius, and $\mathrm{API}_{@ 60 \mathrm{~F}}$ is the gravity of the dead oil measure at $60^{\circ} \mathrm{F}$.

\section{Density model}

The first challenge was to develop a unified model of a set of parameters for the entire range of dead crude oil density with only one equation. Curve fitting by regression methods of the experimental density data with respect to the standard ${ }^{\circ}$ API gravity and temperature was applied. The results were acceptable and well fit by an equation of the following form:

$\rho_{\text {od }}=\bar{a}+\bar{b}\left(\mathrm{API}_{60}{ }^{\circ} F / 60^{\circ} F\right)+\bar{c}(T)$,

where $\rho_{\text {od }}$ is the density of the dead oil in $\mathrm{kg} \mathrm{m}^{-3}$, is the temperature and $\mathrm{API}_{@ 60 \mathrm{~F}}$ is the gravity of the dead oil measure at $60^{\circ} \mathrm{F}$.

The values of $\bar{a}, \bar{b}$ and $\bar{c}$ are $1.072408845,-0.00652625$, and -0.0006639 , respectively, with a regression coefficient $\left(R^{2}\right)$ of 0.98 .

\section{Viscosity model}

Before developing the new viscosity model, understanding the relationship between the input and output variables is essential; specifically, identifying which parameters are insignificant and can be eliminated from the final model and the parameters that are highly correlated with the output. A sensitivity analysis was performed for the main parameters (viscosity $\mu$, density $\rho$, and temperature $T$ ) for all the experimental data (Table 5). The negative correlation coefficient between the dynamic viscosity and temperature shows that whenever the temperature is increased, the viscosity decreases, indicating an inverse correlation between them. The relationship between the viscosity and temperature could be described by Eq. 5 . The positive value of the correlation factor between the density and the viscosity indicates a direct correlation, and the equation for these variables follows the form of Eq. 6 .

$\mu_{\text {od }} \alpha\left(\frac{1}{T^{b}}\right)$

$\mu_{\text {od }} \alpha c \ln \rho_{\text {od }}$.

Consequently, the dead oil viscosity $\left(\mu_{\mathrm{od}}\right)$ is considered to be a function of the absolute value of reservoir temperature $(T)$ and the crude oil density $(\rho)$. After multiple regression analysis of all the experimental viscosity data, and using many forms for a viscosity equation as a function of density and temperature, the results show that the following functional form was set to be presented the data in this work.

$\ln \left(\mu_{\text {od }}\right)=\hat{a}+\frac{\hat{b}}{T^{2}}+\hat{c}\left(\rho_{\text {od }}^{2}\right) \ln \rho_{\text {od }}$.

The correlation parameters for the normal and high temperature ranges must be re-evaluated to generalize the prediction ability of the model to represent the whole set of crude oil viscosity data. The data were divided into two sets based on the temperature range. This division drastically increased the accuracy of the model and reduced its relative error. The model can predict the dead oil viscosity data with an average absolute error of $8 \%$ and an $R^{2}$ of 0.97 . The first set was used with the model for the normal temperature range $20-100{ }^{\circ} \mathrm{C}$, and the second set was used for the high temperature range above $100{ }^{\circ} \mathrm{C}$. The values were evaluated and tested using different techniques, such as curve fitting, nonlinear regression, and the square method. Table 6 shows the values for $\hat{a}, \hat{b}$, and $\hat{c}$ for each section of the data set, where the viscosity is in $\mathrm{cP}$, the temperature is in ${ }^{\circ} \mathrm{C}$, and the density is in $\mathrm{g} \mathrm{cm}^{-3}$.

\section{Assessment of the proposed density and viscosity models}

Statistical analyses were conducted randomly for 376 data points of the 30 dead crude oil samples. The results based on these numbers were randomly divided between training and testing parts in a ratio of $3: 1$. 
Table 6 Values of the correlation parameters for the viscosity model (Eq. 7)

\begin{tabular}{llc}
\hline Designation & $\begin{array}{l}\text { Low temperature } \\
\left(20-100{ }^{\circ} \mathrm{C}\right)\end{array}$ & $\begin{array}{l}\text { High temperature } \\
\left(\text { above } 100{ }^{\circ} \mathrm{C}\right)\end{array}$ \\
\hline$\hat{a}$ & 10.76 & 7.93 \\
$\hat{b}$ & 275.3 & 309.60 \\
$\hat{c}$ & 107.8 & 61.51 \\
\hline
\end{tabular}

\section{Density model evaluation}

Fluid densities have been estimated using Standing (1957) method, with $\mathrm{n}$ correction factors. The correction factor $\Delta \rho_{p}$ is the change in density due to the effect of pressure on the oil, and $\Delta \rho_{T}$ is the change in density due to the thermal expansion of oils as described in Eq. 8 (Sattarin et al. 2007; Standing 1957).

$\rho=\rho_{\mathrm{sc}}+\Delta \rho_{p}+\Delta \rho_{T}$.

According to Standing's relationships;

$$
\begin{aligned}
\Delta \rho_{p} & =\left[0.167+(16.181) 10^{0.0425 \rho_{s c}}\right]\left(\frac{P}{1000}\right) \\
\Delta \rho_{T} & =\left[0.013+152.4\left(\rho_{s c}+\Delta \rho_{p}\right)^{-2.45}\right] x(T-520) \\
& -\left[8.1\left(10^{-6}\right)-(90.06) \times 10^{-0.764\left(\rho_{s c}+\Delta \rho_{p}\right)}\right](T-520)^{2}
\end{aligned}
$$

where $P$ is the pressure in bar, $T$ is the temperature in Rankin, and $\rho_{\mathrm{sc}}$ is the measured density at standard conditions $\mathrm{kg} \mathrm{m}^{-3}$.

The pressure correction factor was neglected because all the measurements were done on dead oil samples under normal pressure. The reliability and accuracy of the data from the density measurements were checked by comparing the experimental values with the predicted values using (1) standing density model and (2) the proposed density model. The results were satisfactory with an $R^{2}$ of $(0.98$ and 0.99 ) and an average absolute error $(\varepsilon)$ of 0.61 and $0.04 \%$, respectively, as shown in Fig. 1a and b.

Another way of evaluating the density model is by applying the cubic equation of state (EoS) that was developed by (Peng and Robinson 1976).

$P=\frac{R_{g} T}{v-b}-\frac{a(T)}{v(v+b)+b(v-b)}$,

where $P$ is the pressure, $T$ is the temperature, $v$ is the molar volume, $R_{\mathrm{g}}$ is the universal gas constant.

This equation can also be written using the compressibility factor $(\mathrm{Z})$.

$$
\begin{aligned}
& Z^{3}-(1-B) Z^{2}+\left(A-3 B^{2}-2 B\right) Z-\left(A B-B^{2}-B^{3}\right) \\
& \quad=0
\end{aligned}
$$
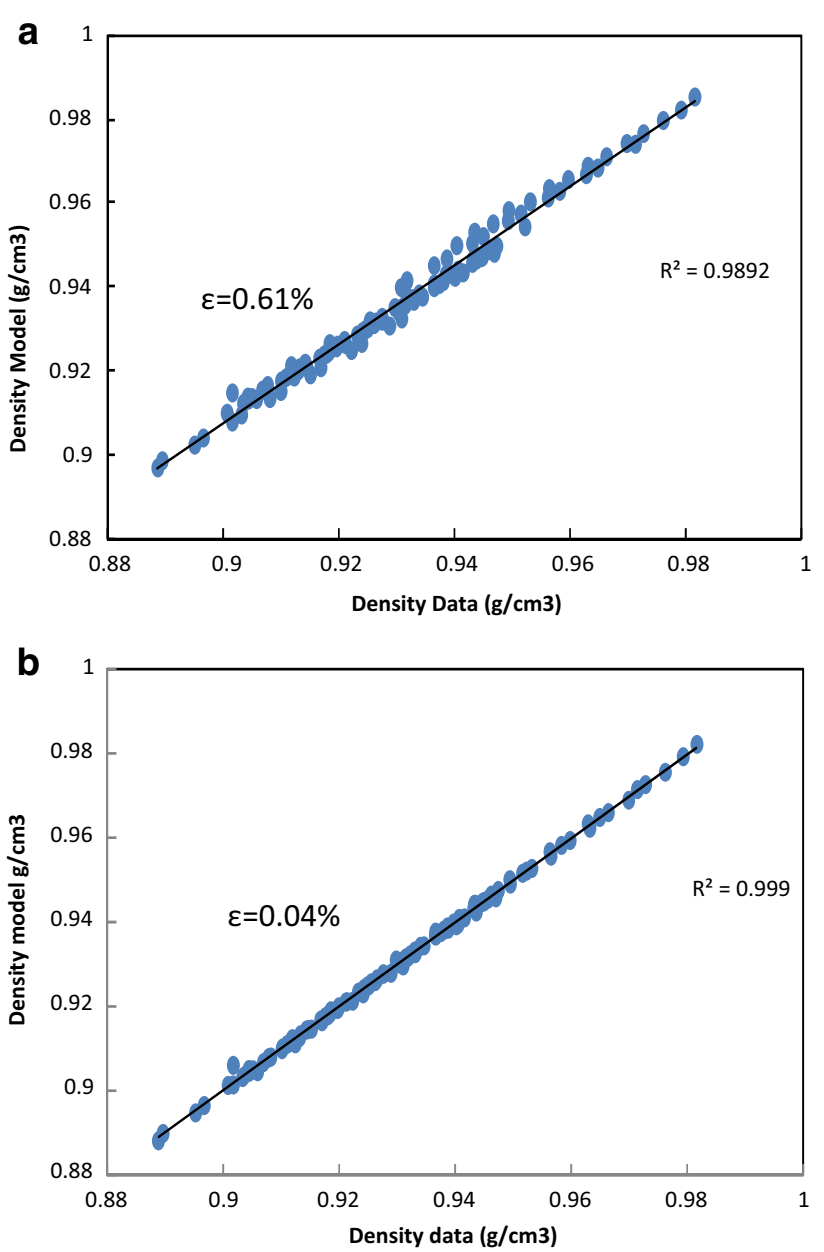

Fig. 1 a Relationship between experimental density and the Standing model. b Relationship between experimental density and the proposed model

The parameters $(a)$ and $(b)$ in Eq. 10 are calculated by applying the equation at the critical point.

$a\left(T_{\mathrm{c}}\right)=\alpha \frac{R_{\mathrm{g}}^{2} T_{\mathrm{c}}^{2}}{P_{\mathrm{c}}}$

$b\left(T_{\mathrm{c}}\right)=\beta \frac{R_{\mathrm{g}} T_{\mathrm{c}}}{P_{\mathrm{c}}}$

$a(T)=a\left(T_{\mathrm{c}}\right)\left(1+m\left(1-T_{\mathrm{r}}^{1 / 2}\right)\right)^{2}$

$b(T)=b\left(T_{\mathrm{c}}\right)$

$m=0.37464+1.54226 \omega+0.26992 \omega^{2}$,

where $T_{\mathrm{c}}$ and $P_{\mathrm{c}}$ are the critical temperature and pressure, respectively, $T_{\mathrm{r}}$ is the reduced temperature $T_{\mathrm{r}}=T / T_{\mathrm{c}}$, and $\omega$ is the acentric factor.

The value of $\alpha$ is 0.45724 , and the value of $\beta$ is 0.0778 , and these values can be empirically tuned for better results. The values of critical parameters $\left(P_{\mathrm{c}}, T_{\mathrm{c}}\right.$, and $\left.\omega\right)$ are calculated using the correlations developed by (Kesler and Lee 1976). The average of the pseudo-component for each 
group of hydrocarbons in each distillation range was calculated. In addition, the sample mid-true boiling points at 20,50 , and $80 \%$ distilled were determined $\left(T_{\mathrm{b}}\right)$, as shown in Table 2. After calculating the compressibility factor $(\mathrm{Z})$, the molar volume was calculated, and this value was then converted to density using the molecular weight. After tuning the EoS parameters, the average error was successfully dropped to $2.3 \%$, compared with $22.5 \%$ before tuning.

\section{Viscosity model evaluation}

To check the ability of the proposed viscosity model to present all experimental data, cross plots of the measured and predicted viscosity values were used. The results for the low-temperature region were in good agreement, with the average relative absolute error approximately $8.5 \%$. The training and testing parts also had the same error, as depicted in Fig. 2. For the high temperature region, the average relative error was $7 \%$ for the training part and $8 \%$ for the testing part, as shown in Fig. 3. The relationship between viscosity and temperature for randomly selected samples with different API values (high, medium, and low) at normal and high temperatures is shown in Fig. 4. One of the main challenges in this study is that most of the existing models in the literature are limited to certain ranges of temperature, API value, and viscosity. Some of the data points had viscosity values higher than $10,000 \mathrm{cP}$, whereas the maximum limit for the others models is approximately $600 \mathrm{cP}$. Ten different models (Beal 1946; Beggs and Robinson 1975; Elsharkawy and Alikhan 1999; Glaso 1980; Hossain et al. 2005; Kartoatmodjo and Schmidt 1994; Labedi 1992; Naseri et al. 2005; Petrosky and Farshad 1995; Standing 1947) were used to determine the capability of these models to predict the experimental viscosity data. Some results showed good agreement with the data, whereas other models had poor

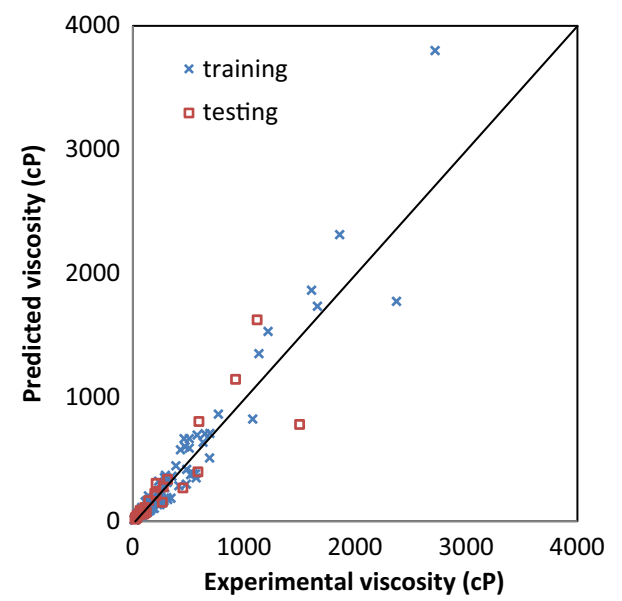

Fig. 2 Comparison of the predicted and measured viscosities using the low-temperature model $\left(20{ }^{\circ} \mathrm{C}<T<100{ }^{\circ} \mathrm{C}\right)$ predictive capabilities. The main source of error in the models' predictions is perhaps individual limitations and/or the availability of accurate experimental data. Table 7 shows a summary of the ten evaluated models with all their data ranges. All the models were used to reproduce the data points regardless of their viscosity, temperature, or API limitations. The model created by Standing in 1947 gave the most acceptable results among the ten published models. Several approaches were used to compare these models with the proposed model of the data under study. These approaches were (A) squaring the Pearson product moment correlation coefficient, (B) relative error, (C) standard deviation, and (D) cross plots.

First approach: squaring the Pearson product moment correlation coefficient Figure 5 is a bar chart showing the measured values of the linear regression correlation coefficient, $R^{2}$, for all the models. This chart shows the $R^{2}$ value of the proposed model with the 10 tested models. The proposed model has the highest $R^{2}$ value $(0.97)$, followed by the model proposed by Standing (0.95). Two other models by Hosain et al. and Elsharkawy and Alikhan (1999) have correlation coefficients of (0.91) and (0.89), respectively. The lowest $R^{2}$ value, 0.19 , is for the model by Labedi (1992).

Second approach: relative error The relative average error test was performed by calculating the absolute percent error between the calculated and the measured value using the following expression;

$\varepsilon=\left|\frac{\text { Measured }- \text { calculated }}{\text { Measured }}\right| \times 100$.

The average values of the absolute errors are shown in Table 8 , and the distribution of the errors for all the models

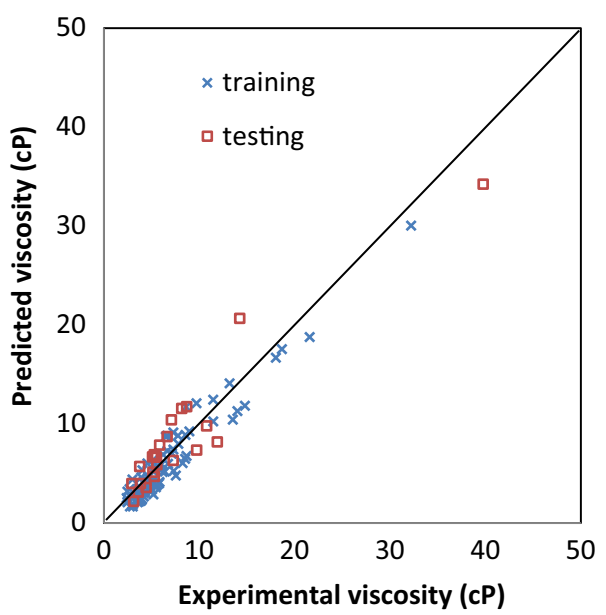

Fig. 3 Deviation of the experimental from the predictive values using the high-temperature model $\left(T>100{ }^{\circ} \mathrm{C}\right)$ 
Fig. 4 Assessment of the measured viscosity data with the proposed models on randomly selected samples with different API values

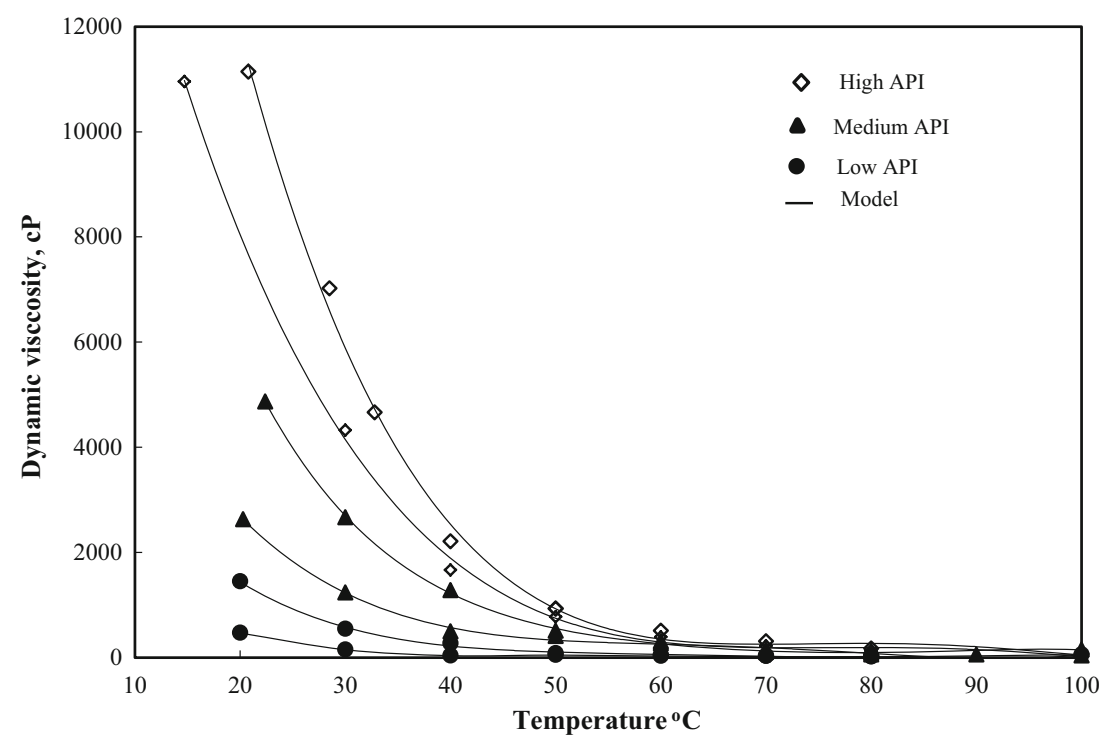

Table 7 Summary of the evaluated models, including the API, temperature, and viscosity limits

\begin{tabular}{|c|c|c|c|c|c|c|}
\hline \multirow[b]{2}{*}{ Author } & \multicolumn{2}{|c|}{ API ${ }_{60}\left({ }^{\circ} \mathrm{F}\right)$} & \multicolumn{2}{|c|}{ Temp. $\left({ }^{\circ} \mathrm{C}\right)$} & \multicolumn{2}{|c|}{$\mu(\mathrm{cP})$} \\
\hline & low & high & low & high & low & high \\
\hline This work 2014 & 11.7 & 18.8 & 20.0 & 160.0 & 1.7 & 11,322 \\
\hline Naseri et al. 2005 & 17 & 44 & 40.6 & 146.1 & 0.75 & 54 \\
\hline Labedi 1992 & 32 & 48 & 37.8 & 152.2 & 0.6 & 4.8 \\
\hline Elsharkawy and Alikhan 1999 & 20 & 48 & 37.8 & 148.9 & 0.6 & 33.7 \\
\hline Beggs and Robinson 1975 & 16 & 58 & 21.1 & 146.1 & - & - \\
\hline Beal 1946 & 10 & 52 & 37.8 & 104.4 & 0.8 & 188 \\
\hline Standing 1947 & 10.1 & 52.5 & 37.8 & 104.4 & 0.86 & 1550 \\
\hline Glaso 1980 & 20 & 48 & 10.0 & 148.9 & 0.6 & 39 \\
\hline Kartoatmodjo and Schmidt 1994 & 14 & 59 & 26.7 & 160.0 & 0.5 & 586 \\
\hline Petrosky and Farshad 1995 & 25.4 & 46.1 & 45.6 & 142.2 & 0.72 & 10.2 \\
\hline Hossain et al. 2005 & 15.8 & 22.3 & 51.1 & 93.3 & 22 & 415 \\
\hline
\end{tabular}

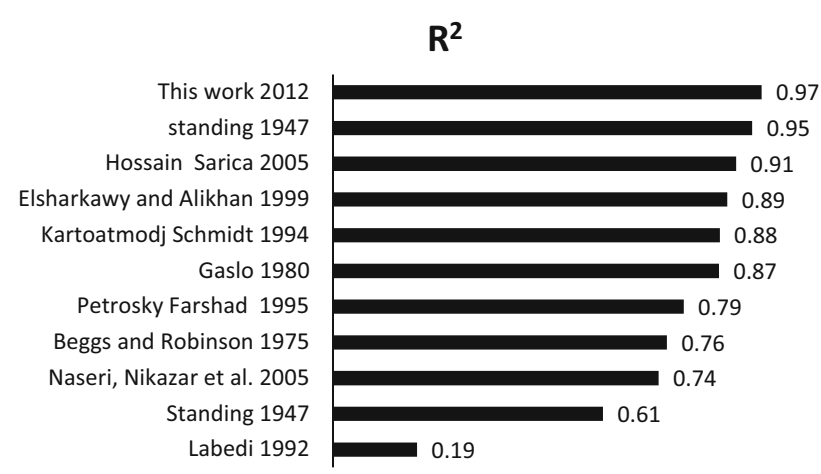

Fig. 5 Bar chart for the $R^{2}$ values for each of the models when applied on our data

is shown in Fig. 6. This distribution shows how this work is the best representative of the studied data with the tightest error distribution. By contrast, the other models have a very wide distribution, which indicates that these models can be applied to these data only within the limitations of each model.

Third approach: standard deviation Another statistical test was performed on the data and the models; a measure of the standard deviation (SD) was performed between the experimental and calculated data with Eq. 10:

$\mathrm{SD}=\sqrt{\frac{\sum_{i=1}^{n}\left(\hat{\mu}_{i}-\mu_{i}\right)^{2}}{n-p},}$,

where $\hat{\mu}_{i}, \mu_{i}, n$, and $p$ are the experimental, predicted values of dynamic viscosity, the number of data points, and the number of parameters, respectively. The results of this test are shown in Table 8. The proposed model shows the lowest SD while the other model do not show a very good result specially when the SD is above $1000 \mathrm{cP}$. 
Fourth approach: cross plots The graphical approach in Fig. 7 shows the behavior of all the tested models against the experimental and calculated values. Some models present a relatively high value of $R^{2}$, but some of these models are inconsistent with real values around the $45^{\circ}$ line, specifically the models of (Naseri et al. 2005) and (Kartoatmodjo and Schmidt 1994). Other models, such as (Beal 1946) and (Labedi 1992), have low $R^{2}$ values, and the predicted data are scattered (Fig. 7). This graphical presentation also shows that the Standing model describes the data with some minor scattering points around the $(y=x)$ line while the proposed model is giving the best prediction without any scattering between the experimental data and the model's measured value.

Table 8 Absolute percentage error ( $\varepsilon$ ) and standard deviation (SD)

\begin{tabular}{lrl}
\hline Model designation & $\varepsilon$ & SD \\
\hline (This work 2014) & 8.0 & 203.7 \\
(Standing 1947) & 39.8 & 220.0 \\
(Naseri et al. 2005) & 76.0 & 219.5 \\
(Beggs and Robinson 1975) & 76.8 & 2158 \\
(Elsharkawy and Alikhan 1999) & 99.5 & 1043 \\
(Hossain et al. 2005) & 119.0 & 1058 \\
(Kartoatmodjo and Schmidt 1994) & 123.0 & 1073 \\
(Petrosky and Farshad 1995) & 125.4 & 932 \\
(Glaso 1980) & 458.8 & 220.7 \\
(Labedi 1992) & 2883.6 & 908.9 \\
(Beal 1946) & 6420.6 & 666.4 \\
\hline
\end{tabular}

\section{Evaluation using worldwide samples}

The proposed model was tested along with the literature models using crude oil from different areas in North America (USDOE 1995) to test its ability to be generalized. Table 9 shows the ranges of these 45 data points. Table 10 shows the average absolute error percent between the predicted value of the viscosity of each model and the experimental results along with the value of $R^{2}$ for each case. The overall result shows that it is not an easy task to generalize a dead oil viscosity model along with the API and temperature.

\section{Application of equation of state to predict the viscosity}

The viscosity was calculated using a transport model that is based on Enskog's theory (Chapman and Gowling 1970). The viscosity was calculated as follows:

$\mu=\mu_{0} b^{\prime} \rho\left[\frac{1}{b^{\prime} \rho \chi}+0.8+0.7614\left(b^{\prime} \rho \chi\right)\right]$,

where

$b^{\prime} \rho \chi=\frac{v}{R_{\mathrm{g}}}\left[\frac{R}{v-b}-\frac{1}{v(v+b)+b(v-b)}\left(\frac{\partial a(T)}{\partial T}\right)\right]$

$b^{\prime} \rho=\frac{1}{v}\left[b-\frac{1}{R_{\mathrm{g}}}\left(\frac{\partial a(T)}{\partial T}\right)\right]$

$\frac{\partial a(T)}{\partial T}=-a\left(T_{c}\right)\left[\frac{m+m^{2}\left(1-T_{r}^{0.5}\right)}{\left(T T_{c}\right)^{0.5}}\right]$

$\mu_{0}=0.1 \frac{N h}{v} \exp \left(3.8 \frac{T_{\mathrm{b}}}{T}\right)$
Fig. 6 Percentage error distribution on all the data points. Beal and Labedi were excluded from this figure due to the high error values

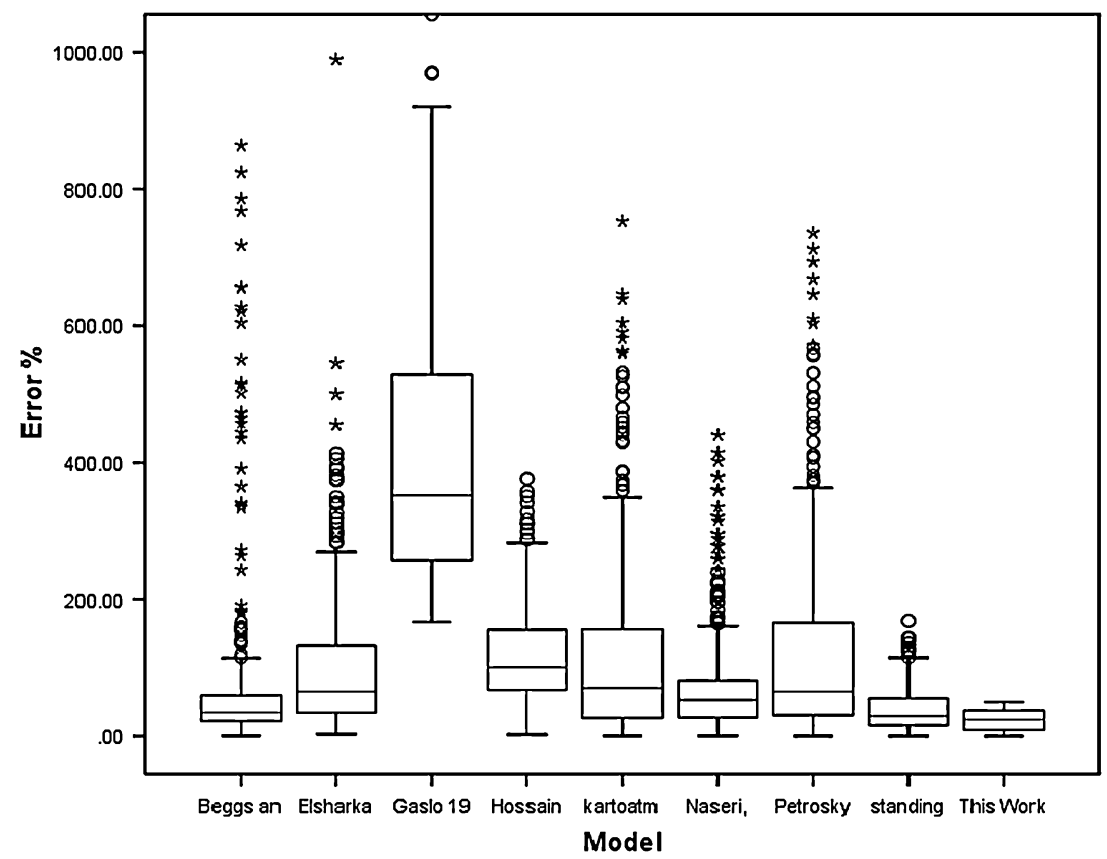


Fig. 7 Deviation of experimental viscosity data from predictive values using proposed model
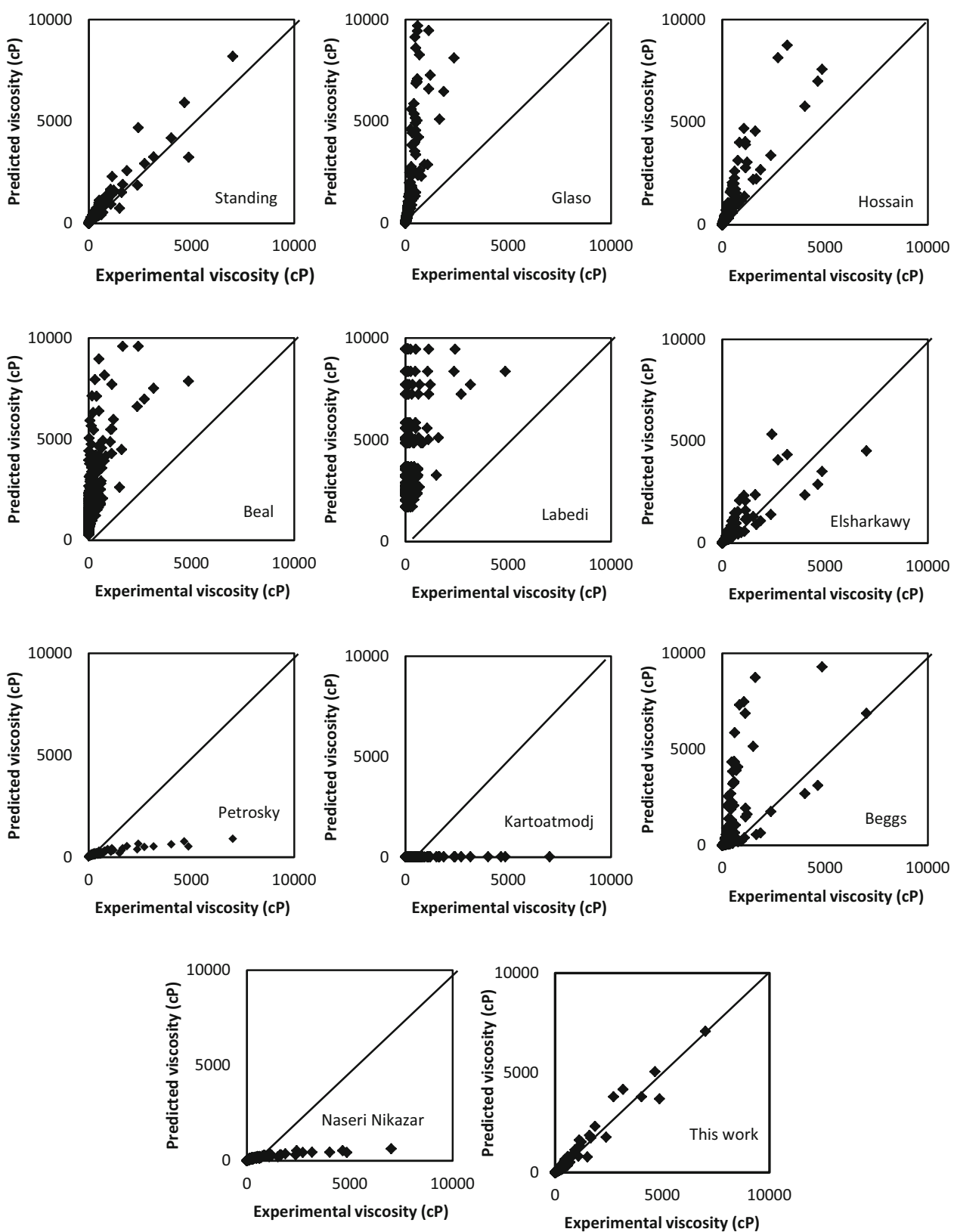

Table 9 Ranges of randomly selected data for testing the model for the 45 international data points

\begin{tabular}{lrrl}
\hline & API & $T\left({ }^{\circ} \mathrm{C}\right)$ & $\mu_{\text {od }}(\mathrm{cP})$ \\
\hline Maximum & 21.8 & 103.7 & 3340 \\
Minimum & 7.1 & 47.5 & 12 \\
Mean & 14.7 & 91.5 & 157.0 \\
\hline
\end{tabular}

where $\mu_{0}$ is the dilute gas viscosity, $\rho$ is the molar density, $b^{\prime}$ is the co-volume, $\chi$ is the value of the equilibrium radial distribution function at a distance equal to the molecular diameter from the center of an individual molecule, and $T_{\mathrm{b}}$ is the boiling point.

The original values of the parameters $\alpha$ and $\beta$ gave an average error of density more than $90 \%$, but after tuning the parameters and using new values of $0.009,0.0058$, respectively, the average error was $80.3 \%$. Another application of the EoS was made but this time using the Pederson corresponding state with the Peng-Robension EoS this trail also gave us a very high absolute error with the value of $126 \%$. Consequently, the published EoS theories are not suitable to represent our experimental viscosity data. Figure 8 shows a cross plot between the experimental viscosity data and the predicted viscosity using EoS. 
Table 10 Results of reproduction of randomly selected data from around the world

\begin{tabular}{ll}
\hline & $R^{2}$ \\
\hline This work 2014 & 0.98 \\
Standing 1977 & 0.96 \\
Beggs and Robinson 1975 & 0.96 \\
Hossain et al. 2005 & 0.94 \\
Elsharkawy and Alikhan 1999 & 0.90 \\
Glaso 1980 & 0.74 \\
Naseri et al. 2005 & 0.27 \\
Kartoatmodjo and Schmidt 1994 & 0.20 \\
Petrosky and Farshad 1995 & 0.15 \\
Beal 1946 & 0.04 \\
Labedi 1992 & 0.04 \\
\hline
\end{tabular}

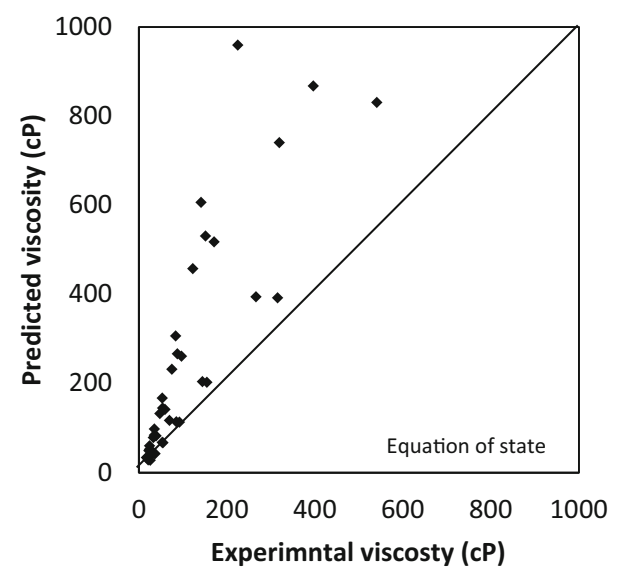

Fig. 8 Deviation of experimental viscosity data from predictive values using EOS

\section{Conclusions}

Although, oils of widely varying compositions can have the same gravity, considerable errors may be introduced when the viscosities of heavy oils are estimated from general viscosity trends and the API gravity. This viscosity model is a function of the absolute value of reservoir temperature $(T)$ and the crude oil density $(\rho)$ which are more valuable and simple to use. Good results of the proposed density model at normal and elevated temperatures could be observed with the average absolute error $(\varepsilon)$ of $0.04 \%$ and the coefficient of determination $R^{2}$ of 0.99 . Several empirical models for estimating the viscosity of dead oils were evaluated using dynamic viscosity data of heavy crude oils from the reservoirs of Middle East. Most of the published models for predicting the dynamic viscosity dead oils are unreliable in a wide temperature range. The assessment of the agreement between the experimental viscosity data and the predicted values indicates that the proposed model successfully represents the experimental data with an average absolute relative error of less than $8 \%$ and coefficients of determination $R^{2}$ of 0.97 and 0.92 at normal and high temperature, respectively. From statistical analysis, the proposed model was demonstrated as one of the best models in comparison with other models published in the literature. The overall result shows that it is not an easy task to generalize a dead oil viscosity model along with the API and temperature as an input for that model. However, this new model is easy to use, provides fair accuracy and precision over a wide range of heavy oil gravities, and could be used to predict better outcomes in future works.

Acknowledgments This work was supported and funded by Kuwait University, Research Grant No. [GE01/07] - Petroleum Fluid Research Center (PFRC) and Research Grant No. [GE03/08]. The authors would also like to acknowledge Research Grant No. [PE 02/08] from where some of the viscosity data were used.

Open Access This article is distributed under the terms of the Creative Commons Attribution 4.0 International License (http:// creativecommons.org/licenses/by/4.0/), which permits unrestricted use, distribution, and reproduction in any medium, provided you give appropriate credit to the original author(s) and the source, provide a link to the Creative Commons license, and indicate if changes were made.

\section{References}

Ahrabi F, Ashcroft SJ, Shearn RB (1987) High pressure volumetric phase composition and viscosity data for a North Sea crude oil and NGL mixtures. Chem Eng Res 67:329-334

Beal C (1946) Viscosity of air, water, natural gas, crude oil and its associated gases at oil field temperature and pressures. Trans AIME 165:94-115

Beggs HD, Robinson JR (1975) Estimating the viscosity of crude oil systems. JPT 1975:1440

Chapman S, Gowling TG (1970) The mathematical theory of nonuniform gases: an account of the kinetic theory of viscosity, thermal conduction and diffusion in gases. Cambridge University Press, Cambridge

Elsharkawy AM, Alikhan AA (1999) Model for predicting the viscosity of Middle East crude oils. Fuel 78:891-903

Glaso O (1980) Generalized pressure-volume-temperature correlation for crude oil system. J Pet Technol 2:785-795

Hossain MS, Sarica C, Zhang HQ (2005) Assessment and development of heavy oil viscosity correlations. In Assessment and development of heavy oil viscosity correlations, international thermal operations and heavy oil symposium. Calgary, Alberta, Canada: Society of Petroleum Engineers

Kartoatmodjo T, Schmidt Z (1994) Large data bank improves crude physical property correlation. Oil Gas J 92:51-55

Kesler MG, Lee BI (1976) Improve prediction of enthalpy of fractions. Hydrocarbon Process 55:153-158

Labedi R (1992) Improved correlations for predicting the viscosity of light crudes. J Pet Sci Eng 8:221-234

Little JE, Kennedy HT (1968) Calculating the Viscosity of Hydrocarbon Systems With Pressure Temperature and Composition. SPE J Journal 8(2):157-162 
Lohrenz J, Bray BC, Clark CR (1964) Calculating viscosities of reservoir fluids from their composition. JPT 16(10):1170-1176

Miller K, Erno B (1995) Use the misuse of hevy oil and bituman viscosity data. In Use the misuse of heavy oil and bituman viscosity data, 46th. Annual technical meeting of the petroleum society of CIM, 93-95. Banff, Alberta, Canada: CIM

Naseri A, Nikazar M, Mousavi-dehghani SA (2005) A correlation approach for prediction of crude oil viscosity. J Pet Sci Eng 47:163-174

Peng DY, Robinson DB (1976) A new two-constant equation of state. Ind Eng Chem Fundam 15:59-63

Petrosky Jr GE, Farshad FF (1995) Viscosity correlations for gulf of mexico crude oils. In Viscosity correlations for gulf of mexico crude oils, SPE production operations symposium. Oklahoma City: Society of Petroleum Engineers

Sattarin M, Modarresi H, Bayat M, Teymori M (2007) New viscosity correlations for dead crude oils. Pet Coal 49:33-39

Standing MB (1947) A pressure-volume-temperature correlation for mixtures of california oils and gases. Drill Prod Pract, American Petroleum Institute, New York, 275-284

Standing MB (1957) Drilling and production practice: API

USDOE, United States Department of Energy (1995) Data from the 1995 US Heavy Oil Database. In Data from the 1995 US Heavy Oil Database 